\title{
Research
}

\section{Millennial-scale change on a Caribbean reef system that experiences hypoxia}

\author{
Blanca Figuerola, Ethan L. Grossman, Noelle Lucey, Nicole D. Leonard and Aaron O'Dea
}

B. Figuerola (https://orcid.org/0000-0003-4731-9337) $\square$ (bfiguerola@gmail.com), N. Lucey (https://orcid.org/0000-0002-7975-8521) and A. O’Dea (https://orcid.org/0000-0001-5495-4764) অ (odeaa@si.edu), Smithsonian Tropical Research Inst. (STRI), Balboa, Republic of Panama. BF also at: Dept of Marine Biology and Oceanography, and Inst. of Marine Sciences (ICM-CSIC), Barcelona, Spain. AO also at: Dept of Biological, Geological and Environmental Sciences, Univ. of Bologna, Bologna, Italy. - E. L. Grossman (https://orcid.org/0000-0002-1045-6939), Dept of Geology and Geophysics, Texas A\&M Univ., College Station, TX, USA. - N. D. Leonard (http://orcid.org/0000-0003-2578-7738), Radiogenic Isotope Facility, School of Earth and Environmental Sciences, Univ. of Queensland, Brisbane, Queensland, Australia.

\section{Ecography}

44: 1270-1282, 2021

doi: 10.1111/ecog.05606

Subject Editor: Kate Lyons Editor-in-Chief: Miguel Araújo Accepted 4 June 2021
Coastal hypoxia has become an increasingly acknowledged threat to coral reefs that is potentially intensifying because of increased input of anthropogenic nutrients. Almirante Bay (Caribbean Panama) is a semi-enclosed system that experiences hypoxia in deeper waters which occasionally shoals onto shallow coral reefs, suffocating most aerobic benthic life. To explore the long-term history of reefs in the bay we extracted reef matrix cores from two reefs that today experience contrasting patterns of oxygenation. We constructed a 1800-year-long record of gastropod assemblages and isotope compositions from six U-Th chronologically-constrained reef matrix cores. We extracted two cores from each reef at $3 \mathrm{~m}$ water depth and two additional cores from a deeper part $(4.8 \mathrm{~m})$ of the hypoxia-exposed reef. Results show that the deeper part of the hypoxic reef slowed in growth and stopped accreting approximately 1500 years BP while the shallow part of the reef continued to accrete to the present day, in agreement with a model of expanding hypoxia at this time. Our proxy-based approach suggests that the patterns of increasing herbivores and decreasing carbon isotope values in the deeper part of the hypoxic reef may have been driven by an increase in hypoxia via eutrophication caused by either natural changes or human impacts. Similar patterns in these paleoindicators occurred in the shallow part of the hypoxic reef during the last few decades. This suggests that the deep water hypoxia may be expanding to depths as shallow as $3 \mathrm{~m}$ and that shallow reefs are at greater risk due to increased human activity.

Keywords: Caribbean sea, environmental proxies, historical ecology, microgastropods, palaeoindicators, stable isotopes

\section{Introduction}

Coastal hypoxia, traditionally defined as the depletion of seawater dissolved oxygen (DO) to concentrations less than $2 \mathrm{mg} \mathrm{l}^{-1}$, can occur in systems with stratified waters. Oxygen decline is commonly attributed to eutrophication arising from both natural and anthropogenic processes (Diaz and Rosenberg 2008, Rabalais et al. 2010). Excess

(C) 2021 The Authors. Ecography published by John Wiley \& Sons Ltd on behalf of Nordic Society Oikos This is an open access article under the terms of the Creative Commons Attribution License, which permits use, distribution and reproduction in any medium, provided the original work is properly cited. 
nutrients can increase algal biomass and fluxes of organic material to bottom waters, fueling microbial respiration that leads to oxygen depletion (Diaz and Rosenberg 2008).

Although increasing hypoxia has long been recognised as a rising global issue for many marine coastal ecosystems (Diaz and Rosenberg 1995, 2008, Breitburg et al. 2018), it was not generally considered as a major threat to coral reefs until relatively recently (Altieri et al. 2017; although see Lapointe and Clark 1992). This perspective may be more a reflection on the relatively poor monitoring of many tropical reefs, the apparent ephemerality of hypoxic events on reefs and the challenges to post-event diagnoses (Altieri et al. 2017, Hughes et al. 2020). Fortuitous monitoring led to the first major hypoxic event being observed in detail on coral reefs in Almirante Bay, Caribbean Panama in 2010 (Altieri et al. 2017). A similar event was also observed in 2017 (Johnson et al. 2018), and detailed monitoring and research on these reefs is documenting the frequency of these events, interpreting the hydrographic processes responsible and unravelling their ecological and evolutionary impacts on reef life.

The 2010 and 2017 hypoxia events documented in Almirante Bay were both episodic and short-lived, lasting less than five days. Both resulted in the formation of geographically delineated 'dead zones' and widespread damage to the fringing coral reef ecosystems (Fig. 1) in waters deeper than 3-4 m depth (Altieri et al. 2017, Johnson et al. 2018). The Almirante Bay may be naturally prone to hypoxia because it is semienclosed with limited inflow from the open ocean (Kaufmann and Thompson 2005, Gudnitz et al. 2020), has a low tidal range, is protected from winds, and receives high rainfall. All of these characteristics increase the chance that waters will stratify and surface oxygen will fail to diffuse or become mixed into benthic waters (Diaz and Rosenberg 2008). The increasing eutrophication from runoff of nutrients that has been observed in the region (Seemann et al. 2014), likely caused by deforestation and fertilization from local banana plantations and other human effluents (Stephens 2008, Cramer 2013, Aronson et al. 2014, Graniero et al. 2016, O’Dea et al. 2020, Gudnitz et al. 2020), could explain the perceived increased frequency of hypoxia in the bay. Alternatively, episodic hypoxic events may have naturally occurred for millennia, and simply been unobserved due to the lack of long-term proxy data and ephemerality of hypoxia. Long-term environmental and ecological changes have been reconstructed using reef cores (Cramer et al. 2017, 2020) but these were taken on reefs outside the most hypoxic part of the bay (colored red in Fig. 1). Notwithstanding, one of these studies (Cramer et al. 2020) reported an increase in the proportion of infaunal deposit- and suspension-feeding bivalve communities over the last 1000 years and suggested this may be evidence for a gradual decrease in oxygen levels within the reef sediments over time.

A recent study showed that DO concentration and, to a lesser extent, temperature, are the most important conditions to consider when predicting environmental impacts on a key reef herbivore in the bay, the sea urchin Echinometra lucunter (Lucey et al. 2020a). However, there remain uncertainties in the predicted effect of climate change on oxygenation depletion because diverse factors, other than increasing temperature, may interact such as eutrophication, ocean acidification, sea-level rise and land cover (Altieri and Gedan 2015).

In this study, we quantified the abundances of microgastropods $(<5 \mathrm{~mm})$, which are valuable environmental
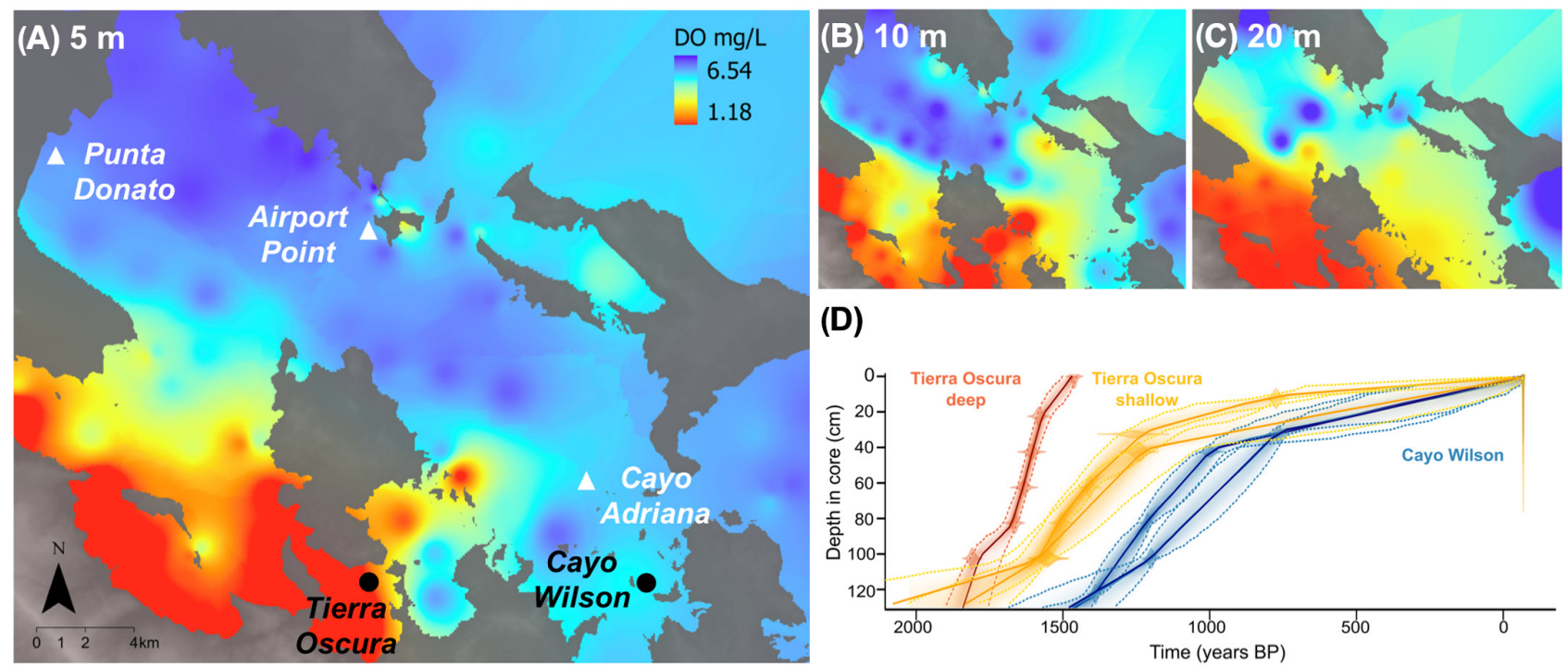

(D)

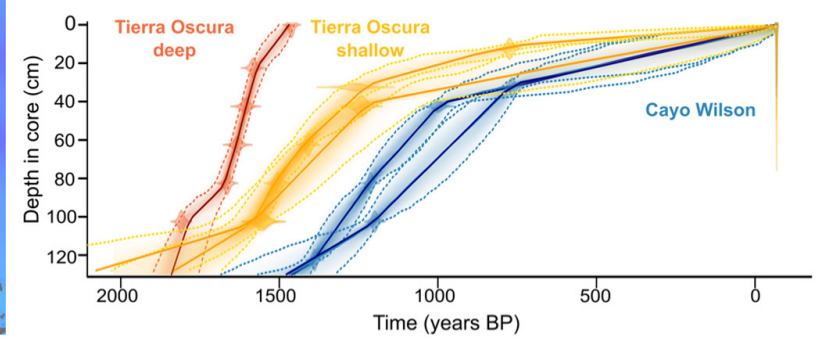

Figure 1. Sampling sites and reef accretion trends. Maps of Almirante Bay showing sites sampled in this and previous studies (black and white, respectively) and the spatial distribution of hypoxia at 5 (A), 10 (B) and $20 \mathrm{~m}$ (C) depths (September 2017). DO range at each map: $5 \mathrm{~m}=6.54-1.18 \mathrm{mg} \mathrm{l}^{-1} ; 10 \mathrm{~m}=6.24-0.24 \mathrm{mg} \mathrm{l}^{-1} ; 20 \mathrm{~m}$ : 6.54-0.20 $\mathrm{mg} \mathrm{l}^{-1}$. (D) Bayesian age-depth models for all the cores (except the poorly-dated core from Tierra Oscura deep) using the R package rbacon (Blaauw and Christen 2011). Darker colors indicate more likely calendar ages, dotted lines indicate $95 \%$ confidence intervals and each solid line shows the 'best fit' based on the weighted mean age for each depth. 
proxies in many marine benthic communities because of their high diversity, and ecological roles, relatively short generation times and good preservation in the fossil record from hundreds to thousands of years (Kidwell and Bosence 1991, Kidwell 2001, Geiger et al. 2007). Microgastropods can also be recovered from cores in substantial numbers, providing high resolution records. Their wide range of feeding modes, life habits, reproductive strategies and life histories leads to a variety of functional roles in reef ecosystems which can provide information on habitats and environments (Fredston-Hermann et al. 2013) and on the occurrence of taxa without fossil remains (e.g. polychaetes) (Kay et al. 1998).

The oxygen isotope compositions of mollusc shells $\left(\delta^{18} \mathrm{O}_{\text {shell }}\right)$ are also a powerful archive of past conditions, reflecting the seawater isotopic composition and temperature on daily to millennial timescales (Schöne et al. 2004, Surge and Barrett 2012, Prendergast and Stevens 2014, Fortunato 2015, Grossman et al. 2019). $\delta^{18} \mathrm{O}_{\text {shell }}$ follows a negative quasi-linear relationship with temperature $(--0.2 \%$ per ${ }^{\circ} \mathrm{C}$; Epstein et al. 1953), but also reflects the $\delta^{18} \mathrm{O}$ of ambient water $\left(\delta^{18} \mathrm{O}_{\text {water }}\right)$, which covaries with salinity (Schmidt 1998). For example, on Panama's Caribbean coast, $\delta^{18} \mathrm{O}_{\text {water }}$ varies from +0.5 to $+1.3 \%$ for a salinity range from 33 to 36 psu (Tao et al. 2013). $\delta^{13} \mathrm{C}_{\text {shell }}$ generally reflects the $\delta^{13} \mathrm{C}$ of dissolved inorganic carbon $\left(\delta^{13} \mathrm{C}_{\mathrm{DIC}}\right)$. In shallow environments, $\delta^{13} \mathrm{C}_{\mathrm{DIC}}$ varies as a function of photosynthesis, respiration, ocean-atmosphere gas exchange and mixing with ${ }^{13} \mathrm{C}$-depleted freshwater runoff, but can also be influenced by mollusc metabolism (McConnaughey and Gillikin 2008, Strauss et al. 2012a).

To examine environmental and ecological changes over millennia in fringing reefs that experiences hypoxia (Tierra Oscura) and limited hypoxia (Cayo Wilson), we used stable isotopes and gastropod assemblages in reef matrix cores from Almirante Bay.

\section{Methods}

\section{Study area}

Almirante Bay is a semi-enclosed coastal lagoon $\left(-450 \mathrm{~km}^{2}\right.$ surface area) bordered by mangroves and delimited by the Bocas del Toro Archipelago (Guzmán et al. 2005). The bay experiences high rainfall $\left(-3000 \mathrm{~mm} \mathrm{year}^{-1}\right.$; Paton 2019). Seawater temperatures are typically higher close to the mainland relative to offshore due to the restricted nature of water circulation (Kaufmann and Thompson 2005). Surface salinities of 30-34 psu can fall to 20 psu during heavy rain (Kaufmann and Thompson 2005). Tidal range is small $(<0.5$ m; Fig. 1), and water exchange with the Caribbean Sea occurs through three narrow passages (Kaufmann and Thompson 2005). Due to the local weather conditions and hydrogeomorphology, Almirante Bay experiences seasonal or perennial oxygen depletion in bottom waters, which can extend close to the surface (Lucey et al. 2020b).
The reefs under study, Tierra Oscura and Cayo Wilson, fringe small mangrove-lined cays close to small creeks that experience periodic flooding (Fig. 1). Circulation models suggest flow strengths are comparable, but with higher water retention times in Tierra Oscura than Cayo Wilson ( $\mathrm{Li}$ and Reidenbach 2014). Tierra Oscura is also located closer to the mainland and therefore likely experiences greater freshwater input and experiences higher water temperatures (Fig. 1). These conditions promote stratification and increased nutrient input, and appear to explain why hypoxic conditions are more common around Tierra Oscura compared to Cayo Wilson (Fig. 1) (Lucey et al. 2020b).

\section{Environmental measurements}

To augment existing environmental data in Almirante Bay (D’Croz et al. 2005, Guzmán et al. 2005, Kaufmann and Thompson 2005, Seemann et al. 2014, Altieri et al. 2017, Lucey et al. 2020b), we made new DO and temperature measurements. We assessed the spatial extent of hypoxia at 5, 10 and approximately $20 \mathrm{~m}$ throughout Almirante Bay using a YSI multiparameter sonde (YSI EXO2 and EXO optical DO Smart Sensor) on 26 September 2017 at 83 sites (Fig. 1). Data points were interpolated with Kriging methods using ArcGIS to visualize spatial patterns in DO.

We also deployed optical DO loggers (MiniDOT, PME; YSI Pro2013) at the reef sampling sites and recorded temperature $\left({ }^{\circ} \mathrm{C}\right.$ ) and $\mathrm{DO}$ values every $10 \mathrm{~min}$ (precision of \pm $0.1^{\circ} \mathrm{C}$ and $\pm 5 \%$, respectively) to determine diel variation (2and 9-month and at Tierra Oscura shallow and deep, respectively, and 3-month deployments at Cayo Wilson) between March and November 2018.

\section{Sampling and processing}

Reef matrix cores were collected from Tierra Oscura and Cayo Wilson in March and June, 2018. We used percussion (push) coring with a $3 \mathrm{~m}$-long aluminium irrigation pipe (7.6 $\mathrm{cm}$ external diameter) to extract six cores. At Tierra Oscura, we extracted two replicate cores $-5 \mathrm{~m}$ apart at $2.4 \mathrm{~m}$ depth through living branching Porites reefs and two replicate cores at $4.6 \mathrm{~m}$ depth through a dead branching Porites matrix (Supporting information). At Cayo Wilson, we took two replicate cores at $1.8 \mathrm{~m}$ depth on living branching Porites reefs. At $10 \mathrm{~m}$ depth, there is a sparse reef in Cayo Wilson, while the sediment consists of fine mud and it is covered by anoxic bacterial mats at $10 \mathrm{~m}$ depth in Tierra Oscura (Figuerola et al. unpubl.).

The six cores were split lengthwise, with one half archived and the other half sliced into $5 \mathrm{~cm}$ sections (hereinafter referred as samples). We analysed every second sample starting from the top (most recent) of each core (e.g. 0-5 cm, $10-15 \mathrm{~cm}$ ) for a total of 11 or 12 samples per core. Each sample was first dried, weighed and wet sieved to collect the $2 \mathrm{~mm}$ and $500 \mu \mathrm{m}$ fractions. All gastropod shells in the $2 \mathrm{~mm}$ fraction and a split of the $500 \mu \mathrm{m}$ fraction were picked. Only specimens with a well-preserved apex or aperture (depending 
on species) were counted. Macro- and microgastropod identifications were based on the available literature (Abbott 1974, Kay et al. 1998, Sasaki 2008, Tunnell 2010) and by comparison with the molluscan reference collection in the Tropical Marine Historical Ecology Laboratory (Smithsonian Tropical Research Inst., Panama).

\section{Chronology by U-Th dating corals}

Porites fragments within the cores were U-Th dated $(\mathrm{Nu}$ I Plasma Multi-Collector Inductively-Coupled Plasma Mass Spectrometer, MC-ICP-MS; Radiogenic Isotope Facility, Univ. of Queensland), following procedures and analytical protocols previously described (Clark et al. 2012, Cramer et al. 2017) (Supporting information). From these dates, we estimated accretion rates using linear interpolation between each pair of ages.

\section{Carbon and oxygen isotope analyses of gastropod shells}

Stable isotope analyses were performed on 227 gastropod specimens belonging to six common genera (Anachis, Caecum, Cerithiopsis, Meioceras and Modulus) from the better-dated core at each site (Stable Isotope Geosciences Facility, Texas A\&M Univ.; Supporting information). We analysed 19 core samples, selecting every fourth interval starting from the core-top (e.g. $0-5 \mathrm{~cm}, 20-25 \mathrm{~cm}$ ). When possible, three replicates were analyzed per interval, each with 1-3 specimens of the same genus depending on specimen size (Supporting information). As discussed later, the shells of the carnivore (Anachis) and the parasite (Cerithiopsis) had lower $\delta^{13} \mathrm{C}$ values on average than the herbivores (Caecum, Cerithium, Meioceras, Modulus), presumably due to metabolic effects (e.g. vital effect) or microhabitat effects (e.g. incorporation of ${ }^{13} \mathrm{C}$-depleted pore-water DIC into shell). Therefore, we used $\delta^{13} \mathrm{C}$ data for the shells of herbivores that live in near-surface sediments to capture the isotope signal of bottom waters for the non-parametric locally weighted regression (LOESS) and non-metric multidimensional scaling (NMDS) analyses. Mean $\delta^{18} \mathrm{O}$ and $\delta^{13} \mathrm{C}$ values at the three sites and core-top samples were compared using one-way ANOVA. In ANOVA tests, homogeneity of variances was verified with the Levene'stest. Although the Shapiro-Wilk test revealed that there was a violation of the normality assumption, ANOVA was still used because it is considered a robust test to violations of normality and a more robust analysis than other non-parametric analyses (Box 1953, Lix et al. 1996). Whenever a difference was established in the ANOVA tests, multiple comparisons were performed using the Tukey's HSD test to determine differences between means.

\section{Temporal trends in gastropod community composition}

Relative abundances of gastropod families were calculated for each sample (Supporting information). Each family was later assigned a life mode (functional group) based on the categories described by Todd (2001) (Supporting information). The Pearson correlation was used to test the relationships between isotopes, accretion rates and relative abundance of gastropods within functional groups. Temporal changes in abundance of functional groups and in isotope composition within each core and among the cores were assessed using LOESSsmoothed trend lines using the $\mathrm{R}$ package lattice (Sarkar 2008). Bray-Curtis dissimilarities were calculated and differences in the functional groups between samples and sites were visualized using an NMDS with the metaMDS function ( $\mathrm{R}$ package vegan; Oksanen et al. 2020). The data used were $\log (1+\mathrm{x})$ transformed to reduce ordination stress. Two dimensions were calculated (Legendre and Legendre 1998). Next, an analysis of similarity (ANOSIM) was used to test for significant differences between groups of samples and relationships between functional groups and isotope composition using the envfit function. The function envfit calculates the regression of environmental variables with ordination axes and tests the significance of this regression by permutation test. The matrix of abiotic variables used included carbon and oxygen isotope values. The significance of correlations ( $p$ $<0.05$ ) between gastropod family and isotope compositions was assessed using 999 random permutations of the abiotic variables. All analyses were performed with the $\mathrm{R}$ ver. 3.5.0 (<www.r-project.org $>$ ).

\section{Results}

\section{Chronology and accretion rates of cores}

All six cores were composed of a dense framework of branching corals infilled by a matrix of sandy-muddy carbonate grains. Visually, branching Porites spp. dominated the coral assemblage in all cores, except from the bottom to the 70-90 cm depth section at Cayo Wilson, where Agaricia tenuifolia Dana, 1846 visually dominated in both cores. The twenty ${ }^{230} \mathrm{Th}$ ages obtained from the six cores spanned from 1809 to 766 years BP (before present, i.e. 1950). ${ }^{230} \mathrm{Th}$ age errors $(2 \sigma)$ ranged from \pm 5 to \pm 26 years (Supporting information). The lowest intervals $(100 \mathrm{~cm})$ of the two deeper cores from Tierra Oscura yielded ages of 1809 and 1553 years BP (cores 1 and 2, respectively), while the sole core-top age (core 1) was 1461 years BP, representing the prehistorical period (Fig. 1D; Supporting information). The shallow cores from Tierra Oscura spanned from -1500 years BP $(100 \mathrm{~cm})$ to 814 years BP $(10 \mathrm{~cm})$. Lastly, Cayo Wilson cores provided an age of 1389 years BP at $120 \mathrm{~cm}$ and an age of -68 years $\mathrm{BP}$ at the core-top (inferred from living coral), representing the prehistorical to modern (post-industrial) period. The shift from Agaricia- to Porites-dominance in Cayo Wilson occurred $\sim 1200$ years BP. Reef accretion rates at the shallow Tierra Oscura and Cayo Wilson sites peaked at -1500 years BP and $\sim 1400$ years BP, respectively, and slowed earlier in Tierra Oscura than Cayo Wilson $(-1300$ years BP versus -1000 years BP) (Fig. 1D). 


\section{Modern environmental data}

At Tierra Oscura, temperatures ranged from $27.3^{\circ} \mathrm{C}$ to $33.5^{\circ} \mathrm{C}$ at $2.4 \mathrm{~m}$ depth and from $29.3^{\circ} \mathrm{C}$ to $32.7^{\circ} \mathrm{C}$ at $4.6 \mathrm{~m}$ depth over a 9-(March-November 2018) and 2-month (OctoberNovember 2018) periods, respectively. At Cayo Wilson, temperatures ranged from $27.5^{\circ} \mathrm{C}$ to $31.9^{\circ} \mathrm{C}$ at $1.8 \mathrm{~m}$ over a 3-month (March-May 2019) period (Supporting information).

At Tierra Oscura, DO values ranged from 0.02 to $14.76 \mathrm{mgl}^{-1}$ at $2.4 \mathrm{~m}$ depth and $2.18-6.07 \mathrm{mg} \mathrm{l}^{-1}$ at $4.6 \mathrm{~m}$ depth over 9and 2-month periods, respectively (Supporting information). At Cayo Wilson DO ranged from 2.55 to $8.93 \mathrm{mg} \mathrm{l}^{-1}$ at $1.8 \mathrm{~m}$ depth over a 3-month period (Supporting information).

DO fluctuated diurnally on both shallow reefs with minimum levels occurring at night (Supporting information). The magnitude of DO fluctuations was highest in shallower waters, and can be attributed to metabolic processes (photosynthesis and respiration) (Lucey et al. 2020b). Additionally, the greater variability in DO for Tierra Oscura shallow compared with Cayo Wilson corresponds to severe deep-water hypoxia (Lucey et al. 2020b).

The ranges of temperature and DO generally support the conclusion that hypoxic conditions correspond to warmer temperatures, corroborating previous measures of seasonal conditions in the bay (Lucey et al. 2020b). However, our monitoring data were too short (especially Tierra Oscura deep and Cayo Wilson) and taken during different seasons to detect strong seasonal patterns of hypoxia on the specific reefs and are thus not directly comparable. The spatial analysis showed hypoxic conditions were most severe 1) close to the mainland (Tierra Oscura) compared with the areas closer to the ocean (Cayo Wilson; Fig. 1) and 2) in deeper waters (20 m and $10 \mathrm{~m}$ compared with $5 \mathrm{~m}$; Fig. 1A-C). These findings are supported by eight years of monitoring data (Lucey et al. 2020b).

\section{Isotope signals and patterns in functional groups}

Six sediment cores resulting in 69 samples were analysed for gastropod family composition. Among the 14556 specimens picked, 13269 belonged to 18 families (average of 192.3 specimens/sample; Supporting information). Each family was assigned to one of four functional groups (herbivores, carnivores, sponge parasites and parasites on polychaetes and on echinoderms; Supporting information). Herbivores dominated all reef environments (68\%), followed by parasites (24\%) and carnivores (7\%; Supporting information).

Oxygen and carbon isotope compositions of micro- and macrogastropods averaged $-1.4 \pm 0.4 \%$ and $1.2 \pm 0.9 \%$, respectively. The low variability in $\delta^{18} \mathrm{O}$ reflects the generally narrow range in temperature and salinity. Significantly lower $\delta^{13} \mathrm{C}_{\text {shell }}$ values were found for the epiphytic gastropod Anachis and the parasite Cerithiopsis compared with other taxa $\left(\mathrm{F}=23.59, \mathrm{df}=231, \mathrm{p}=2.2 \mathrm{e}^{-16}\right)$. In particular, significantly lower values were found in Anachis compared with Caecum, Cerithiopsis $(\mathrm{p}<0.001)$ compared with Meioceras $(\mathrm{p}=0.002)$ and Cerithiopsis compared with Caecum, Meioceras and
Modulus ( $\mathrm{p}<0.001)$. This suggests that a vital or microhabitat effect influences the $\delta^{13} \mathrm{C}_{\text {shell }}$ of Anachis and Cerithiopsis, and supports our decision to use only herbivore species for the analyses. This could explain why not all species showed the same isotope trends (Supporting information).

No significant difference in $\delta^{18} \mathrm{O}$ was observed between sites for whole cores $(\mathrm{F}=0.1513, \mathrm{df}=105, \mathrm{p}=0.86)$ or core-tops $(\mathrm{F}=0.56, \mathrm{df}=14, \mathrm{p}=0.58)$. The relatively high variability in $\delta^{13} \mathrm{C}$ reflects the wide range in $\mathrm{DO}$ content in response to relative rates of photosynthesis, respiration and ventilation, superimposed on vital and microhabitat (infaunal) effects (Strauss et al. 2012b). There is no significant difference in mean $\delta^{13} \mathrm{C}_{\text {shell }}$ between sites $(\mathrm{F}=1.72, \mathrm{df}=105$, $\mathrm{p}=0.1877)$; however, the Cayo Wilson core-top has a higher mean $\delta^{13} \mathrm{C}_{\text {shell }}$ than core-tops at Tierra Oscura shallow $(p=0.002)$ and Tierra Oscura deep $(p<0.001)$, as is expected with hypoxia at Tierra Oscura.

At Tierra Oscura deep, $\delta^{13} \mathrm{C}_{\text {shell }}$ values from herbivore species were significantly lower in the two most recent samples relative to the older samples $(\mathrm{F}=12.82, \mathrm{df}=31, \mathrm{p}<0.001$; Fig. 2), consistent with decreasing oxygen content. $A \delta^{18} \mathrm{O}_{\text {shell }}$ decrease from the older to the recent samples was also significant $\left(\mathrm{F}=2.855, \mathrm{df}=31, \mathrm{p}=0.03\right.$; Fig. 2). While $\delta^{18} \mathrm{O}_{\text {shell }}$ decreased overall up-core in the Tierra Oscura deep core, only the difference between core-top samples and $80 \mathrm{~cm}$ section were significant; $p=0.02$ ). A significant decrease of $\delta^{13} \mathrm{C}_{\text {shell }}$ (envfit, $\mathrm{p}=0.03$ ) corresponds to a shift to a community dominated by herbivorous taxa from circa 1800 (or - 1600) to -1500 years BP (Fig. 3; ANOSIM R $=0.432, p=0.019$ ).

At Tierra Oscura shallow, significantly lower $\delta^{13} \mathrm{C}_{\text {shell }}$ values were also found in recent relative to older samples $(\mathrm{F}=3.83$, $\mathrm{df}=26, \mathrm{p}=0.009$; Fig. 2), but the difference in mean $\delta^{18} \mathrm{O}_{\text {shell }}$ values between these samples was not significant $(\mathrm{F}=1.14$, $\mathrm{df}=26, \mathrm{p}=0.36)$. From $-1600($ or -1500$)$ years BP to present, the community shifted from dominance of carnivores to dominance of parasites on polychaetes (Fig. 3; ANOSIM $\mathrm{R}=0.579, \mathrm{p}=0.009$ ). In addition, relative abundance of herbivores increased from -1600 to 1200 years ago (Fig. 3). A significant $\delta^{13} \mathrm{C}_{\text {shell }}$ decrease corresponds to the significantly lower $\delta^{13} \mathrm{C}_{\text {shell }}$ values (envfit, $\mathrm{p}<0.017$; Fig. 3).

At Cayo Wilson, there was no significant difference in $\delta^{13} \mathrm{C}$ and $\delta^{18} \mathrm{O}$ between samples $\left(\delta^{13} \mathrm{C}_{\text {shell }}\right.$ values: $\mathrm{F}=0.80, \mathrm{df}=48$, $\mathrm{p}=0.55 ; \delta^{18} \mathrm{O}_{\text {shell }}: \mathrm{F}=0.74, \mathrm{df}=32, \mathrm{p}=0.60$; Fig. 2). From -1200 to 1100 years BP to present, the community shifted from carnivore dominance to dominance of herbivores and sponge parasites (Fig. 3; ANOSIM $\mathrm{R}=0.6509$, $\mathrm{p}=0.049$ ), coinciding with the brief shift from Agaricia to Porites. The community change did not correlate with changes in isotope composition (envfit, $\mathrm{p}>0.05$ ).

The timing of changes in functional groups in the sites rarely coincided with the shift from fast to slow reef accretion rates (Supporting information). There were strong negative correlations between herbivores and $\delta^{13} \mathrm{C}_{\text {shell }}$ (Pearson's $\mathrm{r}=-0.83$, $\mathrm{p}<0.001), \delta^{18} \mathrm{O}_{\text {shell }}(\mathrm{r}=-0.73, \mathrm{p}<0.01)$, sponge parasites $(\mathrm{r}=-0.82, \mathrm{p}<0.001)$ and carnivores $(\mathrm{r}=-0.78, \mathrm{p}<0.01)$ in Tierra Oscura deep; and between herbivores and sponge parasites $(\mathrm{r}=-0.92, \mathrm{p}<0.001)$ and carnivores $(\mathrm{r}=-0.76$, 

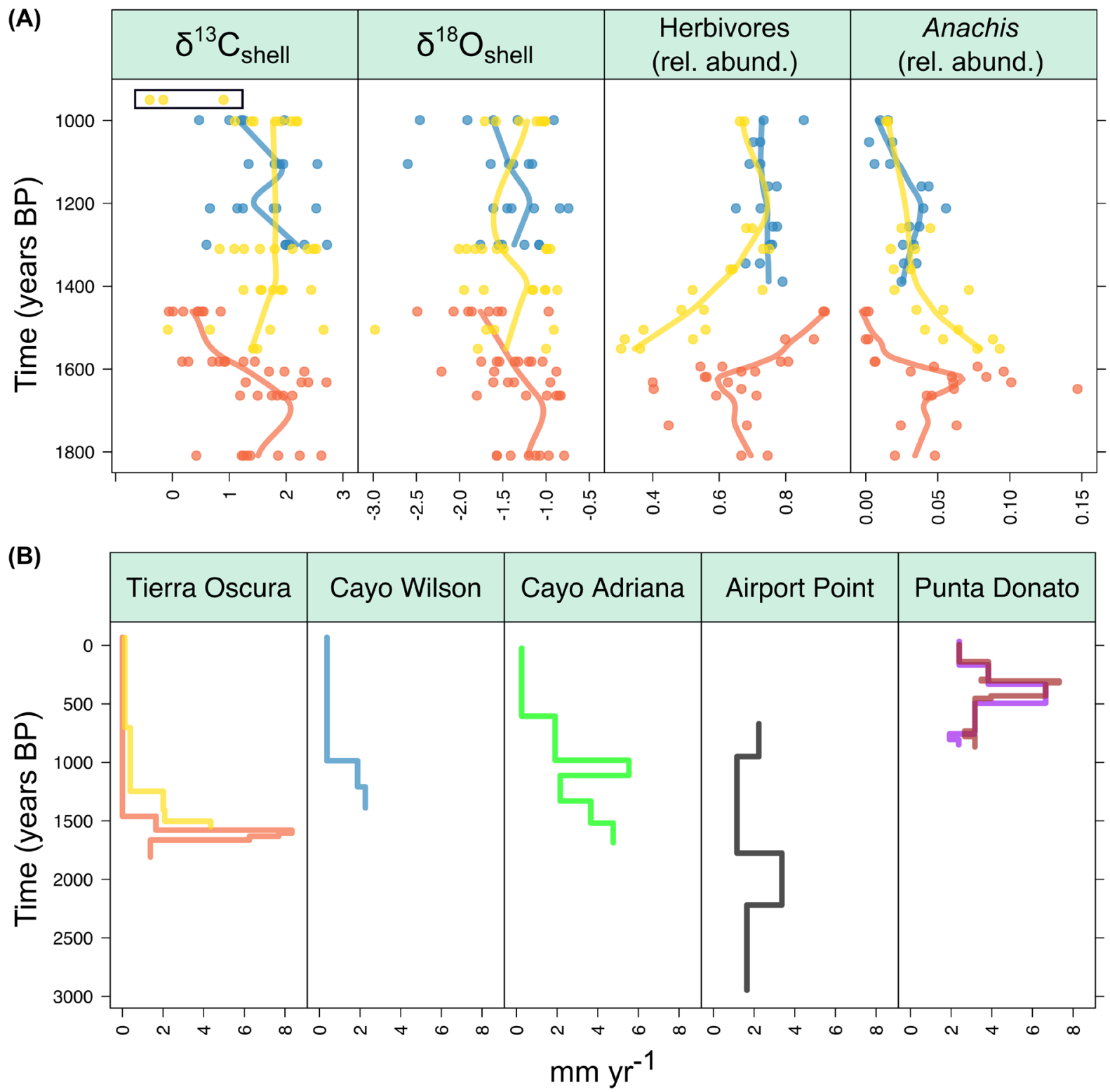

Figure 2. Millennial-scale trends in isotopes and relative abundance of herbivores and a hypoxia-sensitive genus and accretion rates. (A) Isotope paleoenvironmental and biotic data in the hypoxic site Tierra Oscura deep (orange) and shallow (yellow), and the site Cayo Wilson shallow (blue) from $\sim 1800$ to 1000 years $\mathrm{BP}$. Isotope values are from herbivore species. Recent samples with significantly lower mean $\delta^{13} \mathrm{C}_{\text {shell }}$ values are indicated by the black rectangle. (B) Accretion rates in sites sampled in this and previous studies (Cramer et al. 2017, 2020).

$\mathrm{p}<0.01)$ in Tierra Oscura shallow. In Cayo Wilson, there were strong negative correlations between sponge parasites and herbivores $(\mathrm{r}=-0.79, \mathrm{p}<0.01)$ and accretion rates $(\mathrm{r}=-0.90, \mathrm{p}$ $<0.001)$ and a strong positive correlation between carnivores and $\delta^{18} \mathrm{O}_{\text {shell }}(\mathrm{r}=0.87, \mathrm{p}<0.01)$.

\section{Discussion}

We reconstructed environmental and ecological changes over millennia in two Caribbean reefs that today experience contrasting patterns of oxygenation (Fig. 1). In the reef that today experiences hypoxia (Tierra Oscura Deep) we observed increasing herbivore abundances and a decline in isotope values as the deeper portion of the reef transitioned from actively fast accreting to non-accreting -1500 years BP (Fig. 2).

\section{Signs of deterioration in coral reef condition}

Shallow and deeper reefs experienced different patterns of reef accretion (Fig. 2). The deeper portion of Tierra Oscura was actively accreting at relatively fast rates until -1500 years BP, when it stopped accreting, suggesting a rapid decline in coral reef health at this time (Fig. 1D, 2). In contrast, the shallow 


\section{(A) All sites}

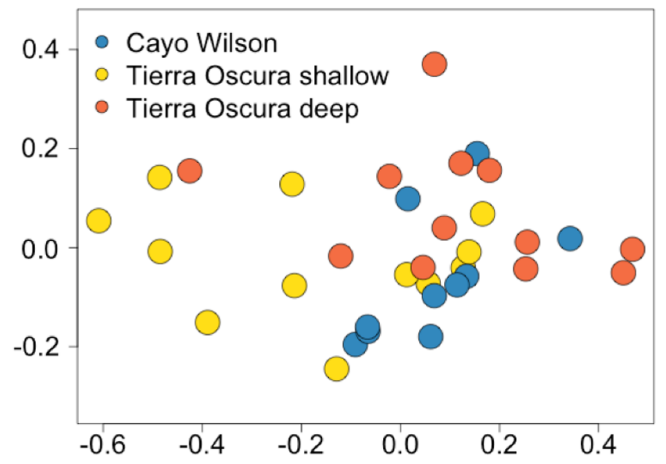

(B) Tierra Oscura deep

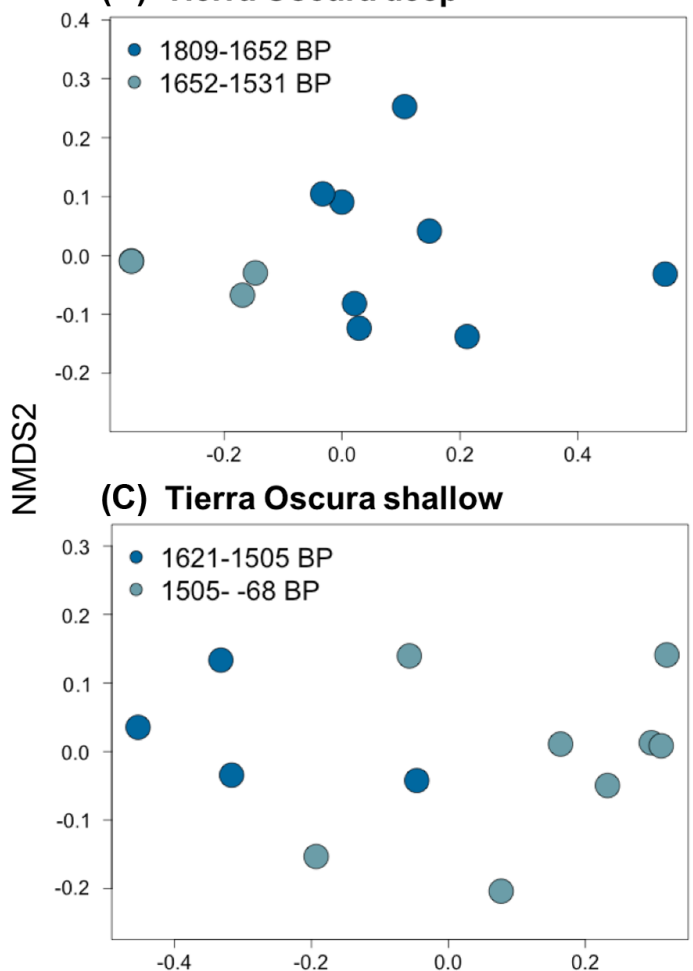

(D) Cayo Wilson

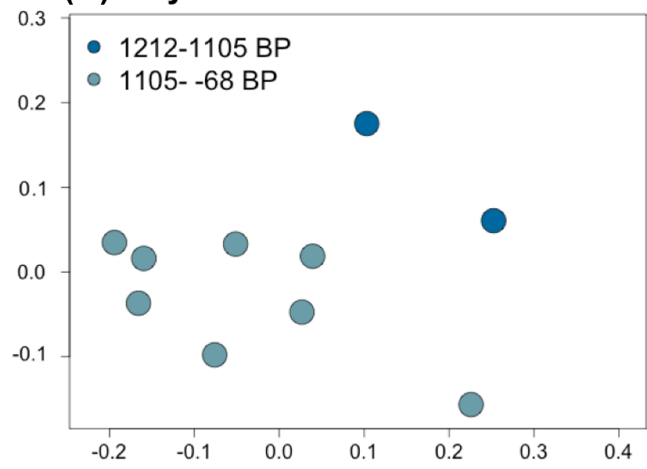

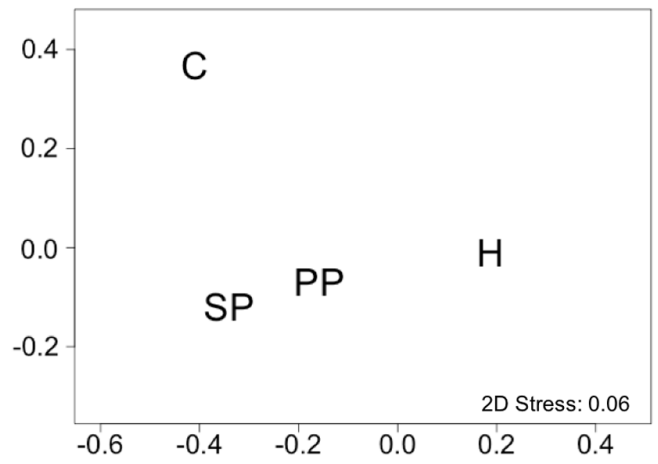
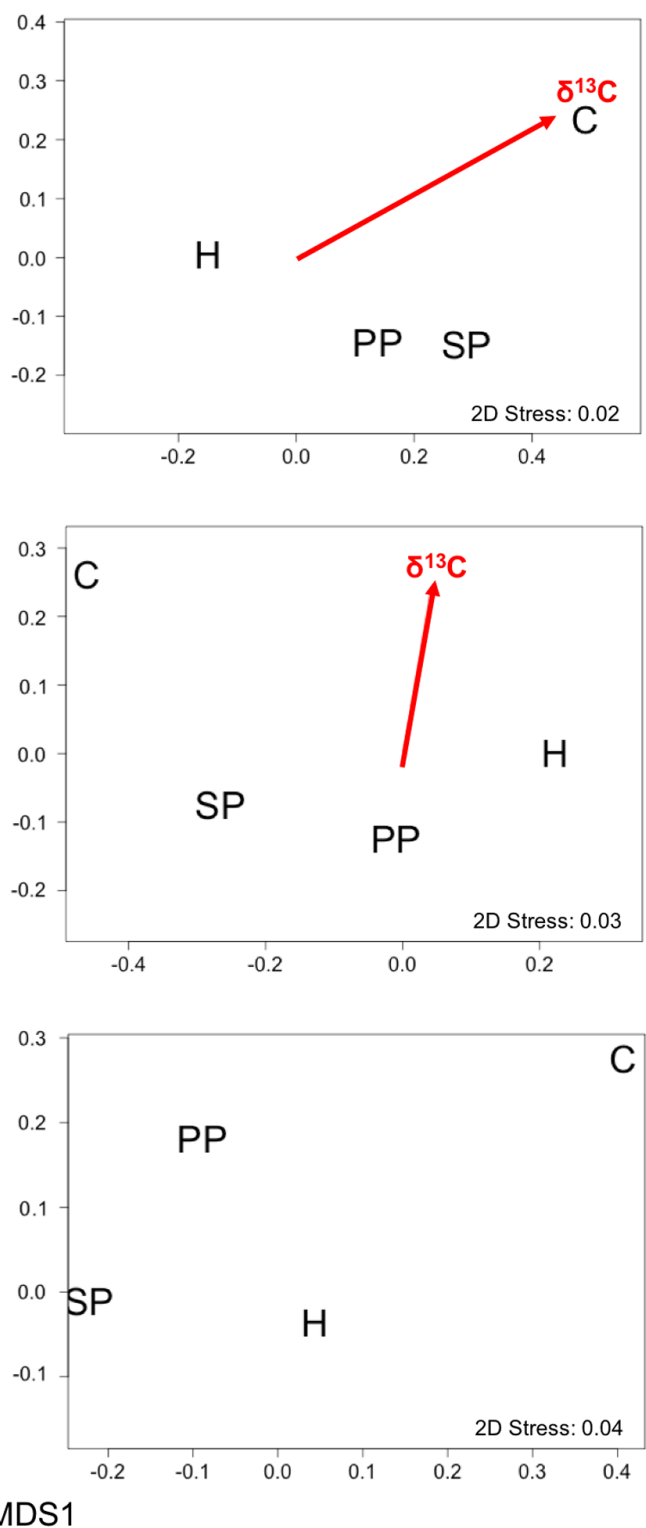

Figure 3. Non-metric multidimensional scaling (NMDS) ordination of functional groups (stress $<0.10$ ). (A) Ordination of samples from all the sites, (B) the hypoxic site Tierra Oscura deep, (C) shallow and (D) the site Cayo Wilson shallow. Significant correlations $(\mathrm{p}<0.05)$ were obtained using the envfit function for carbon isotope composition and were indicated by vectors (arrow points towards higher values). Samples are color-coded by site and years BP. Functional groups: H: herbivores; C: carnivores; SP: sponge parasites; PP: parasites on polychaetes. 
portions of both Tierra Oscura and Cayo Wilson reefs continued to accrete up to today, although at slower rates from -1300 and -1000 years BP, respectively, and both have living corals. Accretion rates did decline in the shallow portions but this was likely a result of limited vertical accommodation space (Spencer 2011) as the reefs approached sea level (Caribbean sea level had more or less stabilized by -1500 BP) (Hibbert et al. 2018). While the decline was contemporaneous with a similar decline observed in a previous study (Airport Point) (Cramer et al. 2020), they occurred at different water depths (6-7 m versus 2-3 m). This may have been caused by an expansion of hypoxia, because Airport Point has more mixed waters and is less prone to hypoxia so the effect would be seen in deeper water. However, further work on ancient and modern conditions at other reefs is required to establish the spatial impacts of hypoxia across the archipelago.

Isotope signals also suggest a prehistoric deterioration of reef health. The deeper portion of Tierra Oscura showed declines in $\delta^{13} C_{\text {shell }}$ values $(p<0.05)$ prior to the cessation of coral growth, which we hypothesized was a result of a historical increase in eutrophication, which likely led to the current hypoxic conditions (Fig. 2). Increasing organic input results in enhanced respiration of organic matter through heterotrophic processes in the water column and bottom sediments from coastal environments that lower dissolved oxygen and produce ${ }^{13} \mathrm{C}$-depleted $\mathrm{CO}_{2}$ (i.e. lower $\delta^{13} \mathrm{C}$ values) (Gooday et al. 2009, Strauss et al. 2012a). This low $\delta^{13} \mathrm{C}_{\text {shell }}$ signal was also observed in the shallow part of the Tierra Oscura reef, although the reef continued to accrete to the present day. Depending on age, the $\delta^{13} \mathrm{C}$ of surface specimens may also be influenced by the Suess effect, which can account for a decline of roughly $0.7 \%$ since 1980 (Gruber et al. 1999). However, this is only half of the shift seen in many taxa (e.g. Anachis, Meioceras, Modulus) (Supporting information).

Overall, $\delta^{18} \mathrm{O}_{\text {shell }}$ decreased with time in the Tierra Oscura deep reef, which, in combination with decreasing $\delta^{13} \mathrm{C}_{\text {shell }}$, suggests increasing input of freshwater (Fig. 2). However, $\delta^{18} \mathrm{O}_{\text {shell }}$ showed no consistent patterns through time in the Tierra Oscura shallow reef. Perhaps a combination of a temporal increase of freshwater input (lower $\delta^{18} \mathrm{O}_{\text {shell }}$ values) and cooling of the top layers of the water (higher $\delta^{18} \mathrm{O}_{\text {shell }}$ values) buffered the effect of salinity variation on $\delta^{18} \mathrm{O}_{\text {shell }}$ in some samples. In particular, Almirante Bay experiences unusual temperature inversions (warmer water at deeper depth) due to a density-driven water column stratification during rainy periods accompanied by clouds and wind, which cool the top layers of water - also registered in this study in September 2018 - which could mask any temporal isotopic signal (Kaufmann and Thompson 2005, Neal et al. 2014).

In this study, all reefs have a past and a current high abundance of low trophic levels (herbivores; including the indicative species Modulus modulus of high organic input), which is indicative of high nutrient levels and high algal biomass (Houbrick 1980, Odum 1985, McClanahan 1992, Fichez et al. 2005, Levin et al. 2009, Cramer et al. 2015). However, only the deeper and shallow portion of the Tierra Oscura reef experienced an increase in the relative abundance of herbivores from -1600 to 1200 years ago, significantly related to decreases of $\delta^{13} \mathrm{C}_{\text {shell }}(\mathrm{p}<0.05)$. The significantly lower mean $\delta^{18} \mathrm{O}_{\text {shell }}$ values of the core-top samples $(\mathrm{p}<0.05)$ and the strong negative correlation between oxygen isotope values and herbivores $(r=-0.73, p<0.01)$ in Tierra Oscura deep also suggest a historical increase of freshwater and nutrient levels compared with the shallow part and Cayo Wilson (Fig. 2). The increase of herbivores may be a response to a historical increase of algae (e.g. turf algae), which are more successful with high nutrient input and are becoming increasingly dominant on many Caribbean coral reefs (Bruno et al. 2009, Vermeij et al. 2010).

\section{Hypoxia as a potential driver of deep reef shutdown}

Our findings suggest hypoxia could have been a driver of deep reef shutdown as the declines in $\delta^{13} \mathrm{C}_{\text {shell }}$ values occurred earlier in the deeper than the shallower part of the hypoxiaexposed reef. In particular, low oxygen typically occurs close to the seafloor and in deeper portions of stratified water columns, where rates of oxygen consumption are likely to be highest and replenishment lowest (Altieri and Diaz 2019). At the Tierra Oscura reef today, living coral extends down to about $3 \mathrm{~m}$ whereupon the substrate shifts sharply to coral rubble which, in places, is covered in mud and bacterial mats indicative of hypoxia. Our historical reconstructions fit the model that this deeper portion of reefs close to the mainland were actively accreting until roughly 1500 years whereupon hypoxia stress led to their shutdown (Fig. 4). By comparing the current spatial distribution of DO in the bay at 5,10 and $20 \mathrm{~m}$ depths (Fig. 1A-C) and available historical data of reef accretion and shutdowns in the bay, we find support for the model of expanding hypoxia from deep to shallow portions over the last millennia. In particular, we found an early decline of the Tierra Oscura deep reef condition $(-1582$ years $\mathrm{BP})$ prior to the shutdown, compared with the timing of the decline of other more exposed fringing reefs from deeper waters (6-7 m depth) in Almirante Bay (Cayo Adriana and Airport Point, -750-650 years BP; Punta Donato, -450 years BP) reported by Cramer et al. (2020) (Fig. 1, 2).

Further, the temporal shift from Agaricia to Porites at both cores in Cayo Wilson at -1200 years BP may signal that conditions worsened at this site. These semi-exposed reefs may have drifted toward the hypoxic reef state of more enclosed systems, with a current dominance of Porites spp. in shallow waters. Agaricia appears to be more affected by high organic carbon and hypoxia than Porites (Laboy-Nieves et al. 2001, Kuntz et al. 2005, Altieri et al. 2017). However, more research is needed to confirm this hypothesis.

Some gastropod taxa and functional groups also provide evidence of historical increases of hypoxic conditions. For example, Anachis, a genus that is sensitive to hypoxic conditions (Díaz Asencio et al. 2016, Kuk-Dzul and DíazCastañeda 2016), declined in relative abundance in the deep and shallow portions of the Tierra Oscura reef from -1600 to 1200 years BP, corroborating the model of worsening DO concentrations at this reef (Fig. 2). In Tierra Oscura shallow, 

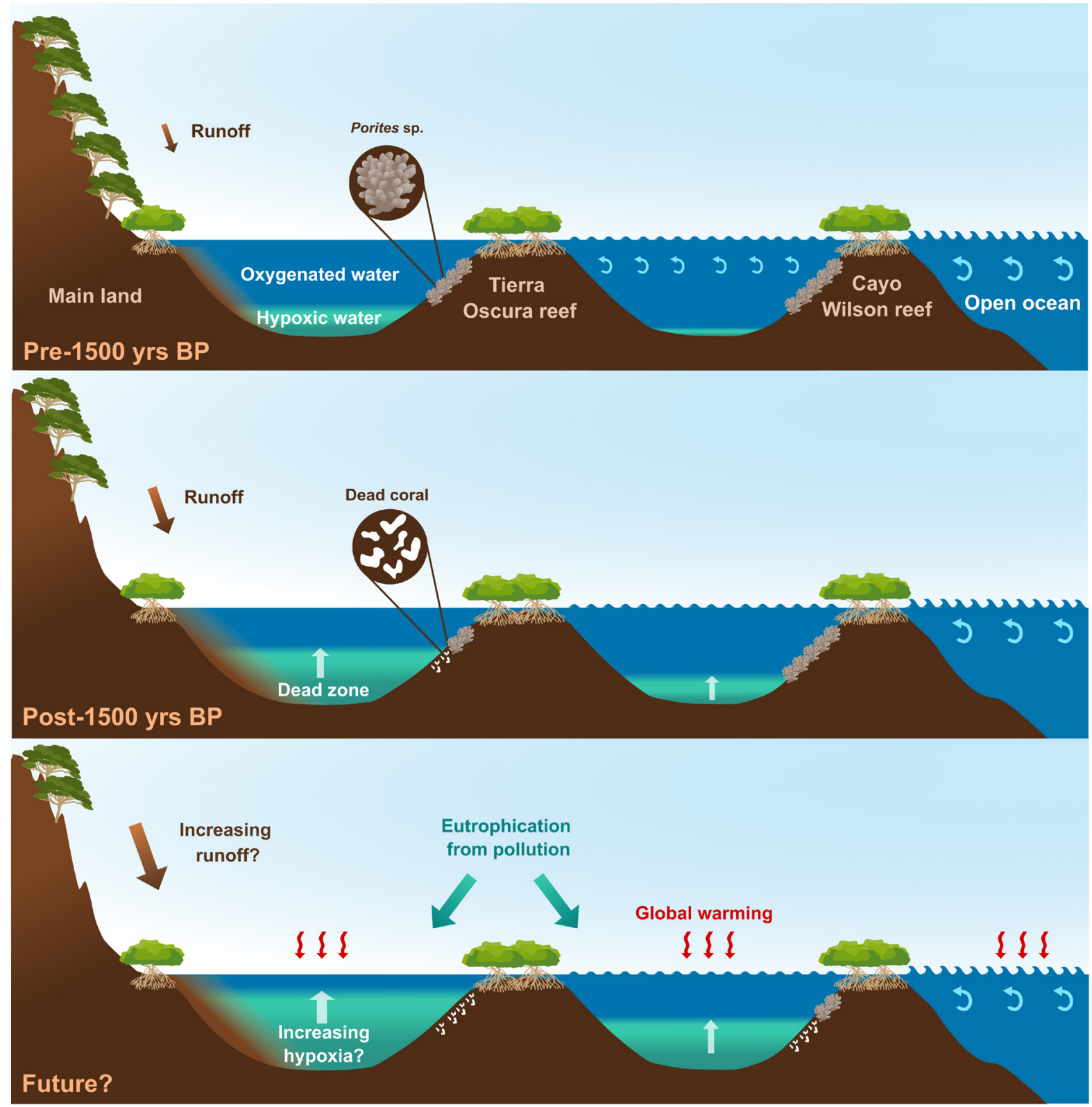

Figure 4. Infographic showing the vertical and horizontal expansion of the hypoxic zone with time in Tierra Oscura and Cayo Wilson. The historical expansion of human populations could result in deforestation on the mainland, initiating an increase in eutrophic and hypoxic conditions, which could lead to the deep reef shutdown in Tierra Oscura approximately 1500 years ago. Shallow reefs are becoming more at risk due to increased anthropogenic activity.

negative correlations between herbivores and sponge parasites $(\mathrm{r}=-0.92, \mathrm{p}<0.001)$ and carnivores $(\mathrm{r}=-0.76, \mathrm{p}<0.01)$ suggest similar patterns of change in both portions of the hypoxic reef. For instance, while sponges and polychaetes can grow under stressful conditions and moderate hypoxia (Kay 1980, Bosch et al. 1987, Fichez et al. 2005), these groups are more susceptible to severe hypoxia than other taxa with reported extensive necrosis effects in the case of the sponges (Riedel et al. 2014, Altieri et al. 2017). In addition, the current lack of a nightly decrease in DO in the deeper portion (Supporting information) reflects a simplified ecosystem with low biodiversity and trophic complexity characteristic of a reef that stopped accreting. While our findings support the hypothesis that coastal eutrophication-induced hypoxia is the driver of the reef shutdown, further studies are required to determine other potential causes.

\section{Natural versus anthropogenic drivers of reef cessation}

The earliest known semi-permanent human settlements in the region, radiocarbon dated to $-3440-2580$ years BP, are 
found at Black Creek, $9 \mathrm{~km}$ west of Bocas del Toro in Costa Rica (Baldi 2011). However, human populations and their impacts on coastal systems appear to have expanded later -1350-1250 years BP, as evidenced from a rapid appearance of shell middens with a wide array of marine resources appearing around Almirante Bay (Linares 1980, Wake and Kay 2013) (Fig. 1). Additionally, by this time conch harvesting was sufficiently intense to have driven declines in size at maturity in Strombus pugilis (O'Dea et al. 2014). Large basaltic metates (grinding tools) found on the non-basaltic islands around Almirante Bay, and remains of oceanic fish species from this period (Wake and Kay 2013), demonstrate that humans were able to travel far using large canoes. It is conceivable that the expansion of human populations at this time resulted in deforestation on the mainland, initiating an increase in eutrophic conditions at Tierra Oscura and the shutdown of the deeper portion of the reef there. However, we caution against such a conclusion without further evidence. The human history of the coastal areas remains undefined outside of two small regions in Almirante Bay (Aguacate Peninsula and Sitio Drago), and there is little information available on the human presence on the Caribbean slope of Bocas del Toro mainland at this time. Records from the broader region, however, does support a wider intensification of human impacts on the Isthmus of Panama at this time. In nearby Costa Rica, Taylor (2011) and Taylor et al. (2013) found evidence that agricultural practices peaked from ca 1718 years BP to 1400 years BP and Anchukaitis and Horn (2005) found evidence of a similar intensification of agriculture ca 1400 years BP. If agriculture did significantly expand at this time, the increased erosion and nutrient runoff may have played a role in environmental changes in Almirante Bay. We suggest this hypothesis be explored further using a variety of geochemical and biological proxies for eutrophication such as other stable isotopes (e.g. sedimentary $\delta^{15} \mathrm{~N}$ ) and preserved remains (e.g. diatom composition), as well as trace elements (Ba, Cd and $\mathrm{Zn}$ ) and lignin (Aronson et al. 2014) and lipid biomarkers (reviewed by Gooday et al. 2009). For instance, Aronson et al. (2014) found peaks in lignin-phenols analyzed from cores extracted in Almirante Bay, which suggest intervals of heavy rainfall.

Non-anthropogenic drivers could also explain the ecosystem changes that occurred in the late Holocene in Almirante Bay. Unfortunately, there are few records of natural environmental change from which to test this possibility. High-resolution stalagmite $\delta^{18} \mathrm{O}$ records reveal a significant ENSO-driven shift in average rainfall patterns on the Isthmus of Panama starting around 1500 years BP, coincident with the deep reef shutdown. However, the shift is from wetter to drier conditions (Lachniet et al. 2004), which would have resulted in less not more run-off from land.

In summary, it is not currently possible to unequivocally assign a driver of the deep-reef shutdown at Tierra Oscura. The limited records that exist suggest shifting rainfall or largescale ENSO patterns cannot explain the ecosystem changes observed. Deforestation driven by human expansion remains a hypothesis that is supported by a mechanism of increased eutrophication driven by land-use changes around Almirante Bay, but a dearth of archeological and other evidence means this question currently remains unresolved.

\section{The future of reefs in Almirante Bay: warning signs}

Our model (Fig. 4) suggests a long-term, gradual expansion of the deep-water hypoxic conditions in Almirante Bay towards shallow waters over time. We see evidence of this first in the deeper portion of the Tierra Oscura reef, which is close to the mainland, around ca 1600 years BP with changes in the ecological composition of gastropod assemblages (herbivores and the hypoxia-sensitive genus) and a shift to lower values of $\delta^{13} \mathrm{C}_{\text {shell }}$ both indicating increases in organic content and low oxygen levels at this time. These shifts preceded the entire shutdown of the deeper part of the reef, implicating expanding hypoxia as the cause of reef shutdown. The shallow portion of this reef continued to accrete, suggesting hypoxic waters did not reach the upper portions of the reef at this time. However, the most recent samples reveal a shift toward lower values of $\delta^{13} \mathrm{C}_{\text {shell }}$ that parallel the shifts that occurred just prior to the deep reef shutdown. This suggests that low oxygen conditions may be encroaching onto the shallow portions of these reefs to an extent that has not previously occurred. If this is the case, the two intense hypoxic events observed in the bay in the last 10 years (Altieri et al. 2017, Johnson et al. 2018, Lucey et al. 2020b) may indeed be reflecting an intensification of hypoxic conditions with no historical precedent. As agriculture and deforestation within the catchment area and human populations expand, the root causes of eutrophication in the Bay are likely to increase. Our historical data suggest that these reefs can rapidly shift from fast accreting, living reefs to nonaccreting 'dead' reefs via the vertical expansion of hypoxia, and that these already 'marginal' reefs (Schlöder et al. 2013) may be approaching an environmental threshold if hypoxic conditions continue to expand. Controlling the drivers of hypoxia such as land clearance, fertilizer use and human population expansion may help, but the processes leading to increased hypoxia are likely to also be exacerbated by global warming (Breitburg et al. 2018).

Acknowledgments - We thank Jorge Morales, Ramiro Solís, Brígida de Gracia, Lucía Rodríguez and Jarrod Scott for help field and logistical support. We thank Dr. Chris Maupin, laboratory manager at the Stable Isotope Geosciences Facility at Texas A\&M Univ. for helping in the isotope analyses. This project and the research visit of BF to Texas A\&M Univ. were financially supported by the Secretaría Nacional de Ciencia y Tecnología e Innovación (SENACYT; 47-2017-4-FID16-239), Sistema Nacional de Investigación (SENACYT), the Scholarly Studies Program (Smithsonian Institution), Smithsonian Tropical Research Institute (STRI), Texas A\&M University and donations from M. Selin and family, J. Bilyk, V. and B. Anders, J. and M. Bytnar and the Young Presidents Organization (Los Angeles Gold Chapter). BF was supported by a STRI postdoctoral fellowship and the postdoctoral fellowships programme Beatriu de Pinós funded by the Secretary of Universities and Research (Government of Catalonia) and by the Horizon 2020 programme of research and innovation of the European Union 
under the Marie Skłodowska-Curie grant agreement no. 801370 (Incorporation grant 2019 BP 00183) and the Juan de la Cierva programme funded by the Ministry of Science and Innovation (Incorporation grant IJCI-2017-31478). With the institutional support of the 'Severo Ochoa Centre of Excellence' accreditation (CEX2019-000928-S).

\section{Author contributions}

Blanca Figuerola: Conceptualization (equal); Data curation (lead); Formal analysis (lead); Investigation (lead); Project administration (lead); Writing - original draft (lead); Writing - review and editing (equal). Ethan L. Grossman: Conceptualization (equal); Formal analysis (supporting); Investigation (supporting); Writing - review and editing (supporting). Noelle Lucey: Formal analysis (supporting); Investigation (supporting); Writing - review and editing (supporting). Nicole D. Leonard: Formal analysis (supporting); Investigation (supporting); Writing - review and editing (supporting). Aaron O'Dea: Conceptualization (equal); Formal analysis (supporting); Investigation (supporting); Project administration (supporting); Supervision (lead); Writing - review and editing (equal).

\section{Data availability statement}

Data available from the Dryad Digital Repository: <https:// dx.doi.org/10.5061/dryad.zs7h44j8s > (Figuerola et al. 2021).

\section{References}

Abbott, R. T. 1974. American seashells: the marine mollusks of the Atlantic and Pacific coasts of North America. - Van Nostrand Reinhold Company, New York, NY.

Altieri, A. H. and Diaz, R. J. 2019. Chapter 24 - Dead zones: oxygen depletion in coastal ecosystems. - In: Sheppard, C. (ed.), World seas: an environmental evaluation, 2nd edn. Academic Press, pp. 453-473.

Altieri, A. H. and Gedan, K. B. 2015. Climate change and dead zones. - Global Change Biol. 21: 1395-1406.

Altieri, A. H. et al. 2017. Tropical dead zones and mass mortalities on coral reefs. - Proc. Natl Acad. Sci. USA 114: 3660-3665.

Anchukaitis, K. J. and Horn, S. P. 2005. A 2000-year reconstruction of forest disturbance from southern Pacific Costa Rica. Palaeogeogr. Palaeoclimatol. Palaeoecol. 221: 35-54.

Aronson, R. B. et al. 2014. Land use, water quality and the history of coral assemblages at Bocas del Toro, Panamá. - Mar. Ecol. Prog. Ser. 504: 159-170.

Baldi, N. F. 2011. Explotación temprana de recursos costeros en el sitio Black Creek (4000-2500 A.P.), Caribe sur de Costa Rica. - Rev. Arqueol. Am. 29: 85-121.

Blaauw, M. and Christen, J. A. 2011. Flexible paleoclimate agedepth models using an autoregressive gamma process. - Bayesian Anal. 6: 457-474.

Bosch, I. et al. 1987. Development, metamorphosis, and seasonal abundance of embryos and larvae of the Antarctic sea urchin Sterechinus neumayeri. - Biol. Bull. 173: 126-135.

Box 1953. Non-normality and tests on variances. - Biometrika 40: 318-335.
Breitburg, D. et al. 2018. Declining oxygen in the global ocean and coastal waters. - Science 359: eaam7240.

Bruno, J. F. et al. 2009. Assessing evidence of phase shifts from coral to macroalgal dominance on coral reefs. - Ecology 90: $1478-1484$.

Clark, T. R. et al. 2012. Spatial variability of initial 230Th/232Th in modern Porites from the inshore region of the Great Barrier Reef. - Geochim. Cosmochim. Acta 78: 99-118.

Cramer, K. L. 2013. History of human occupation and environmental change in Western and Central Caribbean Panama. Bull. Mar. Sci. 89: 955-982.

Cramer, K. L. et al. 2015. Molluscan subfossil assemblages reveal the long-term deterioration of coral reef environments in Caribbean Panama. - Mar. Pollut. Bull. 96: 176-187.

Cramer, K. L. et al. 2017. Prehistorical and historical declines in Caribbean coral reef accretion rates driven by loss of parrotfish. - Nat. Commun. 8: 14160.

Cramer, K. L. et al. 2020. Millennial-scale change in the structure of a Caribbean reef ecosystem and the role of human and natural disturbance. - Ecography 43: 283-293.

D'Croz, L. et al. 2005. The effect of fresh water runoff on the distribution of dissolved inorganic nutrients and plankton in the Bocas Del Toro Archipelago, Caribbean Panama. - Caribb. J. Sci. 41: 414-429.

Díaz Asencio, L. et al. 2016. Two-year temporal response of benthic macrofauna and sediments to hypoxia in a tropical semienclosed bay (Cienfuegos, Cuba). - Rev. Biol. Trop. 64: $177-188$.

Diaz, R. J. and Rosenberg, R. 1995. Marine benthic hypoxia: a review of its ecological effects and the behavioural responses of benthic macrofauna. - Oceanogr. Mar. Biol. Annu. Rev. 33: $245-303$.

Diaz, R. J. and Rosenberg, R. 2008. Spreading dead zones and consequences for marine ecosystems. - Science 321: 926-929.

Epstein, S. et al. 1953. Revised carbonate-water isotopic temperature scale. - Geol. Soc. Am. Bull. 64: 1315-1326.

Fichez, R. et al. 2005. A review of selected indicators of particle, nutrient and metal inputs in coral reef lagoon systems. - Aquat. Living Resour. 18: 125-147.

Figuerola, B. et al. 2021. Data from: Millennial-scale change on a Caribbean reef system that experiences hypoxia. - Dryad Digital Repository, <https://dx.doi.org/10.5061/dryad.zs7h44j8s>.

Fortunato, H. 2015. Mollusks: tools in environmental and climate research. - Am. Malacol. Bull. 33: 310-324.

Fredston-Hermann, A. L. et al. 2013. Marked ecological shifts in seagrass and reef molluscan communities since the mid-Holocene in the southwestern Caribbean. - Bull. Mar. Sci. 89: 983-1002.

Geiger, D. L. et al. 2007. Techniques for collecting, handling, preparing, storing and examining small molluscan specimens. Molluscan Res. 27: 1-45.

Gooday, A. J. et al. 2009. Historical records of coastal eutrophication-induced hypoxia. - Biogeosciences 6: 1707-1745.

Graniero, L. E. et al. 2016. Stable isotopes in bivalves as indicators of nutrient source in coastal waters in the Bocas del Toro Archipelago, Panama. - PeerJ 4: e2278.

Grossman, E. L. et al. 2019. Freshwater input, upwelling and the evolution of Caribbean coastal ecosystems during formation of the Isthmus of Panama. - Geology 47: 857-861.

Gruber, N. et al. 1999. Spatiotemporal patterns of carbon-13 in the global surface oceans and the oceanic suess effect. - Global Biogeochem. Cycles 13: 307-335. 
Gudnitz, M. N. et al. 2021. Foraminiferal communities of a midHolocene reef: Isla Colón, Caribbean Panama. - Palaeogeogr. Palaeoclimatol. Palaeoecol. 562: 110042.

Guzmán, H. M. et al. 2005. A site description of the CARICOMP mangrove, seagrass and coral reef sites in Bocas del Toro, Panama. - Caribb. J. Sci. 41: 430-440.

Hansen, M. C. et al. 2013. High-resolution global maps of 21stcentury forest cover change. - Science 342(6160), 850-853.

Hibbert, F. D. et al. 2018. A database of biological and geomorphological sea-level markers from the Last Glacial Maximum to present. - Sci. Data 5: 180088.

Houbrick, R. S. 1980. Observations on the anatomy and life history of Modulus modulus (Prosobranchia: Modulidae). - Malacologia 20: 117-142.

Hughes, D. J. et al. 2020. Coral reef survival under accelerating ocean deoxygenation. - Nat. Clim. Change 10: 296-307.

Johnson, M. D. et al. 2018. Shallow-water hypoxia and mass mortality on a Caribbean coral reef. - Bull. Mar. Sci. 94: 143-144.

Kaufmann, K. W. and Thompson, R. C. 2005. Water temperature variation and the meteorological and hydrographic environment of Bocas del Toro, Panama. - Caribb. J. Sci. 41: 392-413.

Kay, E. A. 1980. Micromollusks: techniques and patterns in benthic marine communities. - In: Environmental survey techniques for coastal water conference proceedings. Water Resources Research Center and Sea Grant, Univ. of Hawaii at Manoa and Hawaii Water Pollution Control Association, Honolulu, Hawaii, pp. 93-112.

Kay, E. A. et al. 1998. Mollusca: the southern synthesis. Part B. -Fauna of Australia, Vol. 5. CSIRO Publishing, pp. 565-1234.

Kidwell, S. M. 2001. Preservation of species abundance in marine death assemblages. - Science 294: 1091-1094.

Kidwell, S. M. and Bosence, D. W. J. 1991. Taphonomy and timeaveraging of marine shelly faunas. - In: Allison, P. A. and Briggs, D. E. G. (eds), Taphonomy. Releasing the data locked in the fossil record. Plenum, New York, pp. 115-209.

Kuk-Dzul, J. G. and Díaz-Castañeda, V. 2016. The relationship between mollusks and oxygen concentrations in Todos Santos Bay, Baja California, Mexico. - J. Mar. Biol. 2016: e5757198.

Kuntz, N. M. et al. 2005. Pathologies and mortality rates caused by organic carbon and nutrient stressors in three Caribbean coral species. - Mar. Ecol. Prog. Ser. 294: 173-180.

Laboy-Nieves, E. N. et al. 2001. Mass mortality of tropical marine communities in Morrocoy, Venezuela. - Bull. Mar. Sci. 68: 163-179.

Lachniet, M. S. et al. 2004. A 1500-year El Niño/Southern oscillation and rainfall history for the isthmus of Panama from speleothem calcite. - J. Geophys. Res. Atmos. 109(D29: 1-8.

Lapointe, B. E. and Clark, M. W. 1992. Nutrient inputs from the watershed and coastal eutrophication in the Florida keys. Estuaries 15: 465-476.

Legendre, P. and Legendre, L. 1998. Numerical ecology. - Elsevier.

Levin, L. A. et al. 2009. Effects of natural and human-induced hypoxia on coastal benthos. - Biogeosciences 6: 2063-2098.

Li, A. and Reidenbach, M. A. 2014. Forecasting decadal changes in sea surface temperatures and coral bleaching within a Caribbean coral reef. - Coral Reefs 33: 847-861.

Linares, O. F. 1980. Ecology and prehistory of the Aguacate Peninsula in Bocas del Toro. - In: Linares, O. F., Ranere, A. J. (eds), Adaptive radiations in prehistoric Panama. Peabody museum monographs 5. Harvard Univ. Press, pp. 57-66.
Lix, L. M. et al. 1996. Consequences of assumption violations revisited: a quantitative review of alternatives to the one-way analysis of variance F test. - Rev. Educ. Res. 66: 579-619.

Lucey, N. et al. 2020a. Multi-stressor extremes found on a tropical coral reef impair performance. - Front. Mar. Sci. 7: 588764.

Lucey, N. M. et al. 2020b. Oxygen-mediated plasticity confers hypoxia tolerance in a corallivorous polychaete. - Ecol. Evol. 10: 1145-1157.

McClanahan, T. R. 1992. Epibenthic gastropods of the middle Florida keys: the role of habitat and environmental stress on assemblage composition. - J. Exp. Mar. Biol. Ecol. 160: 169-190.

McConnaughey, T. A. and Gillikin, D. P. 2008. Carbon isotopes in mollusk shell carbonates. - Geo-Mar. Lett. 28: 287-299.

Neal, B. P. et al. 2014. When depth is no refuge: cumulative thermal stress increases with depth in Bocas del Toro, Panama. Coral Reefs 33: 193-205.

O'Dea, A. et al. 2014. Evidence of size-selective evolution in the fighting conch from prehistoric subsistence harvesting. - Proc. R. Soc. B 281: 20140159.

O'Dea, A. et al. 2020. Defining variation in pre-human ecosystems can guide conservation: an example from a Caribbean coral reef. - Sci. Rep. 10: 2922.

Odum, E. P. 1985. Trends expected in stressed ecosystems. - BioScience 35: 419-422.

Oksanen, J. et al. 2020. Vegan: community ecology package. - R package ver. 2.5-7.

Paton, S. 2019. Bocas del Toro, platform tower_precipitation. Smithsonian Institution.

Prendergast, A. L. and Stevens, R. E. 2014. Molluscs (isotopes): analyses in environmental archaeology. - In: Smith, C. (ed.), Encyclopedia of global archaeology. Springer, pp. 5010-5019.

Rabalais, N. N. et al. 2010. Dynamics and distribution of natural and human-caused hypoxia. - Biogeosciences 7: 585-619.

Riedel, B. et al. 2014. Effect of hypoxia and anoxia on invertebrate behaviour: ecological perspectives from species to community level. - Biogeosciences 11: 1491-1518.

Sarkar, D. 2008. Lattice: multivariate data visualization with R. Springer.

Sasaki, T. 2008. Micromolluscs in Japan: taxonomic composition, habitats and future topics. - Zoosymposia 1: 147-232.

Schlöder, C. et al. 2013. Benthic community recovery from smallscale damage on marginal Caribbean reefs: an example from Panama. - Bull. Mar. Sci. 89: 1003-1013.

Schmidt, G. A. 1998. Oxygen-18 variations in a global ocean model. - Geophys. Res. Lett. 25: 1201-1204.

Schöne, B. R. et al. 2004. Sea surface water temperatures over the period 1884-1983 reconstructed from oxygen isotope ratios of a bivalve mollusk shell (Arctica islandica, southern North Sea). - Palaeogeogr. Palaeoclimatol. Palaeoecol. 212: 215-232.

Seemann, J. et al. 2014. Assessing the ecological effects of human impacts on coral reefs in Bocas del Toro, Panama. - Environ. Monit. Assess. 186: 1747-1763.

Spencer, T. 2011. Accommodation space. - In: Hopley, D. (ed.), Encyclopedia of modern coral reefs: structure, form and process. Springer, pp. 2-3.

Stephens, C. S. 2008. Outline of history in the province of Bocas del Toro, Panama. - SFS Publications, Eustis, FL.

Strauss, J. et al. 2012a. 100 years of benthic foraminiferal history on the inner Texas shelf inferred from fauna and stable isotopes: preliminary results from two cores. - Cont. Shelf Res. 38: 89-97. 
Strauss, J. et al. 2012b. Stable isotope characterization of hypoxiasusceptible waters on the Louisiana shelf: tracing freshwater discharge and benthic respiration. - Cont. Shelf Res. 47: $7-15$.

Surge, D. and Barrett, J. H. 2012. Marine climatic seasonality during medieval times (10th to 12th centuries) based on isotopic records in Viking Age shells from Orkney, Scotland. - Palaeogeogr. Palaeoclimatol. Palaeoecol. 350-352: 236-246.

Tao, K. et al. 2013. Quantifying upwelling and freshening in nearshore tropical American environments using stable isotopes in modern gastropods. - Bull. Mar. Sci. 89: 815-835. in press.

Taylor, Z. 2011. Spatial variation in organic carbon and stable isotope composition of lake sediments at Laguna. - $\mathrm{PhD}$ thesis, Univ. of Tennessee, USA.
Taylor, Z. et al. 2013. Maize pollen concentrations in Neotropical lake sediments as an indicator of the scale of prehistoric agriculture. - Holocene 23: 78-84.

Todd, J. A. 2001. Introduction to molluscan life habits database. - Natural History Museum, London, UK. < https://nmita. rsmas.miami.edu/database/mollusc/mollusclifestyles.htm $>$.

Tunnell, J. W. 2010. Encyclopedia of Texas seashells: identification, ecology, distribution and history. - Texas A\&M Univ. Press.

Vermeij, M. J. A. et al. 2010. The effects of nutrient enrichment and herbivore abundance on the ability of turf algae to overgrow coral in the Caribbean. - PLoS One 5: e14312.

Wake, T. A. and Kay, M. 2013. Archaeological investigations provide late Holocene baseline ecological data for Bocas del Toro, Panama. - Bull. Mar. Sci. 89: 1015-1035. 